\title{
Effectiveness of GPs in accident and emergency departments
}

\author{
A Joan P Boeke, Marguerite E van Randwijck-Jacobze, Elly MS de Lange-Klerk, \\ Sietske M Grol, Mark HH Kramer and Henriette E van der Horst
}

\section{ABSTRACT}

Background

Many self-attending patients make inappropriate use of accident and emergency departments.

Aim

To determine whether a new care method consisting of the involvement of a GP during the day with the staff of the accident and emergency department of an academic city hospital and application of the Nederlands Triage Systeem by a practice nurse is more effective than usual care.

Design

Before and after intervention design.

Setting

Accident and emergency department in the VU University Medical Center in Amsterdam.

Method

Participants were patients $(n=1527)$ attending the accident and emergency department without a referral, on weekdays from 10.00-17.00 hours, from

1 November 2006 to 30 April 2007. The intervention consisted of a new care method that combined the involvement of a GP in the accident and emergency department and allocation of patients by triage to either the GP or the accident and emergency department physician. Main outcome measures were patient satisfaction, number and type of additional examinations, quality of diagnosis, process time, and treatment time.

\section{Results}

Patient satisfaction with the treatment increased significantly. Compared to the usual care method, this new care method resulted in a $13 \%$ decrease in additional examinations. The percentage of incorrect diagnoses $(1 \%)$, as a measure of quality of care, was similar with the two methods. The mean process time decreased from 93 to 69 minutes $(P<0.001)$. The mean treatment time decreased from 60 to 35 minutes $(P<0.001)$.

\section{Conclusion}

The new care method resulted in greater patient satisfaction and maintained the quality of care, with fewer additional examinations. It reduced both the process time and the treatment time.

Keywords

emergency medical services; efficiency; general practitioners; quality of health care; triage.

\section{INTRODUCTION}

In the Netherlands, patients are supposed to consult their GP for all new health complaints. During the day they can visit the general practice in which they are registered, and after office hours they can go to their local primary care service. If the GP is of the opinion that specialist care is necessary, the patient will be referred accordingly.

Nevertheless, many patients immediately seek medical help in a hospital. Of all the patients who attend an accident and emergency department in large Dutch hospitals, $70 \%$ do so on their own initiative, without being referred by a GP or brought in by ambulance. ${ }^{1}$ These self-attenders do have an acute medical problem, but they are not always in need of acute medical care. This behaviour leads to inappropriate use of healthcare services, and results in increasing waiting time for patients in the accident and emergency department. This phenomenon is not only seen in the Netherlands: it is an international problem. ${ }^{2,3}$ The majority of such self-attenders might be treated more adequately by a GP, and treatment is more efficient if the 'right' problem is treated by the 'right' doctor. Studies have been undertaken to

AJP Boeke, PhD, senior researcher, GP; ME van RandwijckJacobze, principal researcher, GP; EMS de Lange-Klerk, $P h D$, GP, epidemiologist; SM Grol, head of the academic network of general practitioners of VU University Medical Center, health scientist; $\mathrm{MHH}$ Kramer, $M D, P h D$, head of emergency department, internist; HE van der Horst, PhD, professor in general practice, head of department of general practice, GP, VU University Medical Center, Amsterdam, The Netherlands.

Address for correspondence

Dr A Joan P Boeke, VU University Medical Center, Department of General Practice, PO Box 7057, 1007 MB Amsterdam, The Netherlands. E-mail: ajpboeke@wxs.nl

Submitted: 14 September 2009; Editor's response: 23 November 2009; final acceptance: 12 February 2010.

() British Journal of General Practice

This is the full-length article of an abridged version published in print. Cite this article as: Br J Gen Pract 2010; DOI: 10.3399/bjgp10X532369. 
investigate the determinants of inappropriate use of the accident and emergency department. Some authors conclude that health-seeking behaviour might be improved; others expect it to meet with limited success. ${ }^{4,5}$ Dale et al compared the costeffectiveness of GPs, registrars, and senior house officers in the treatment of primary care patients in an accident and emergency department. ${ }^{6}$ They identified important benefits of GP involvement in terms of resource utilisation with no detrimental effect on outcome. Cost-effective substitution of primary by secondary care resources was also described by Roberts and Mays and Lee et al. ${ }^{7,8}$

The present study developed a new care method based on two elements:

- involvement of a GP in the accident and emergency department; and

- appropriate allocation of patients to either the GP or the accident and emergency department physician according to the new Nederlands Triage Systeem. ${ }^{9}$

The study aimed to determine whether this new care method in an accident and emergency department of a busy academic city hospital (the VU University Medical Center, Amsterdam) was more effective than usual care in terms of greater patient satisfaction, fewer additional examinations, shorter waiting and process time, and maintenance of the quality of care. The study was carried out during day time because the waiting time for self-attenders during regular hours increased up to 4 hours at the hospital of the VU University Medical Center; at the same time GPs were present at the university general practice during regular hours.

\section{METHOD}

\section{Design}

A before and after comparative study was carried out of the implementation of a new care method in the accident and emergency department of a university medical centre in the city of Amsterdam.

\section{Population}

From 1 November 2006 to 30 April 2007, 2102 patients who attended the accident and emergency department on weekdays during the day (10.00-17.00 hours) were invited to participate. The exclusion criteria were: referral by a GP, brought in by ambulance, under 16 years of age with no legal guardian present, insufficient knowledge of the Dutch language, and mentally impaired. A total of 1527 patients were willing to participate in the study. During the reference period, from 1 November 2006 to 1 February 2007, 832 patients were enrolled in the

\section{How this fits in}

Internationally, the inappropriate use of the accident and emergency department is a problem. Previous studies show that in the Netherlands $70 \%$ of all patients attending an accident and emergency department do so on their own initiative, seeking medical help for a problem that does not always need acute care. The majority of such self-attenders might be treated more adequately by a GP. This study developed a new care method, adding a GP to the staff of the accident and emergency department and triage by a nurse. The results of this

experimental study show that this new care method had a very positive impact on patients' satisfaction, time management, efficiency, and cost-effectiveness of care, with no decrease in the quality of diagnosis.

study, and during the experimental period from 1 February 2007 to 30 April 2007, 695 patients were enrolled.

\section{Intervention}

Usual care method. In the usual care method, selfattenders checked in at the reception desk. The receptionist asked the patient a number of medical questions to determine whether there was an acute life-threatening health problem. If so, a nurse immediately accompanied the patient to see a doctor. If not, the patient was invited to participate in the study, received oral and written information, and was asked to give informed consent. Thereafter the patient was treated by the accident and emergency department doctor.

New care method. In the new care method, the selfattender checked in at the reception desk and was immediately directed to the triage nurse. After triage, the nurse allocated the patient to either the GP or the accident and emergency department physician, according to the Nederlands Triage Systeem. In the latter case, the nurse determined whether the patient could wait or had to be seen immediately by the accident and emergency department physician. All patients who were not immediately in need of emergency help were asked to participate in the study, after giving informed consent. Patients allocated to the GP were seen by either a GP or a GP trainee. The GP trainee was supervised by a GP. All participating patients (allocated to GP and to physician emergency department) were included in the analysis.

\section{Measurements}

For all self-attenders, the reason for the visit, the symptoms, and the medical history were recorded by the receptionist on a standardised form. The following demographic data were also collected: age, sex, nationality, level of education, and 
comorbidity. Any other visits to the accident and emergency department during the trial period were also registered.

Patient satisfaction was measured with the validated patient satisfaction emergency department questionnaire developed by Visser and modified and used by the Erasmus University Medical Center in Rotterdam. ${ }^{10}$ After their visit, all patients were asked by the research assistants to fill in the questionnaire immediately. Alternatively, they could take the questionnaire home and return it by mail, or they could receive an electronic version of the questionnaire and return it by email.

Data on process time were collected from the patient charts. Administrative personnel recorded the time of the patient's arrival and departure, and the physician recorded the time at which the consultation started and ended. The process time (from arrival until departure), and the treatment time (from start of consultation until departure) were calculated. Data from the hospital financial administration and medical office (a database used in the accident and emergency department to record requests for additional examinations) were collected to determine the use of additional diagnostic tests.

To evaluate the quality of the diagnosis, the GPs
Figure 1.

Inclusion/exclusion with whom the patients were registered were sent a letter informing them about their patient's diagnosis

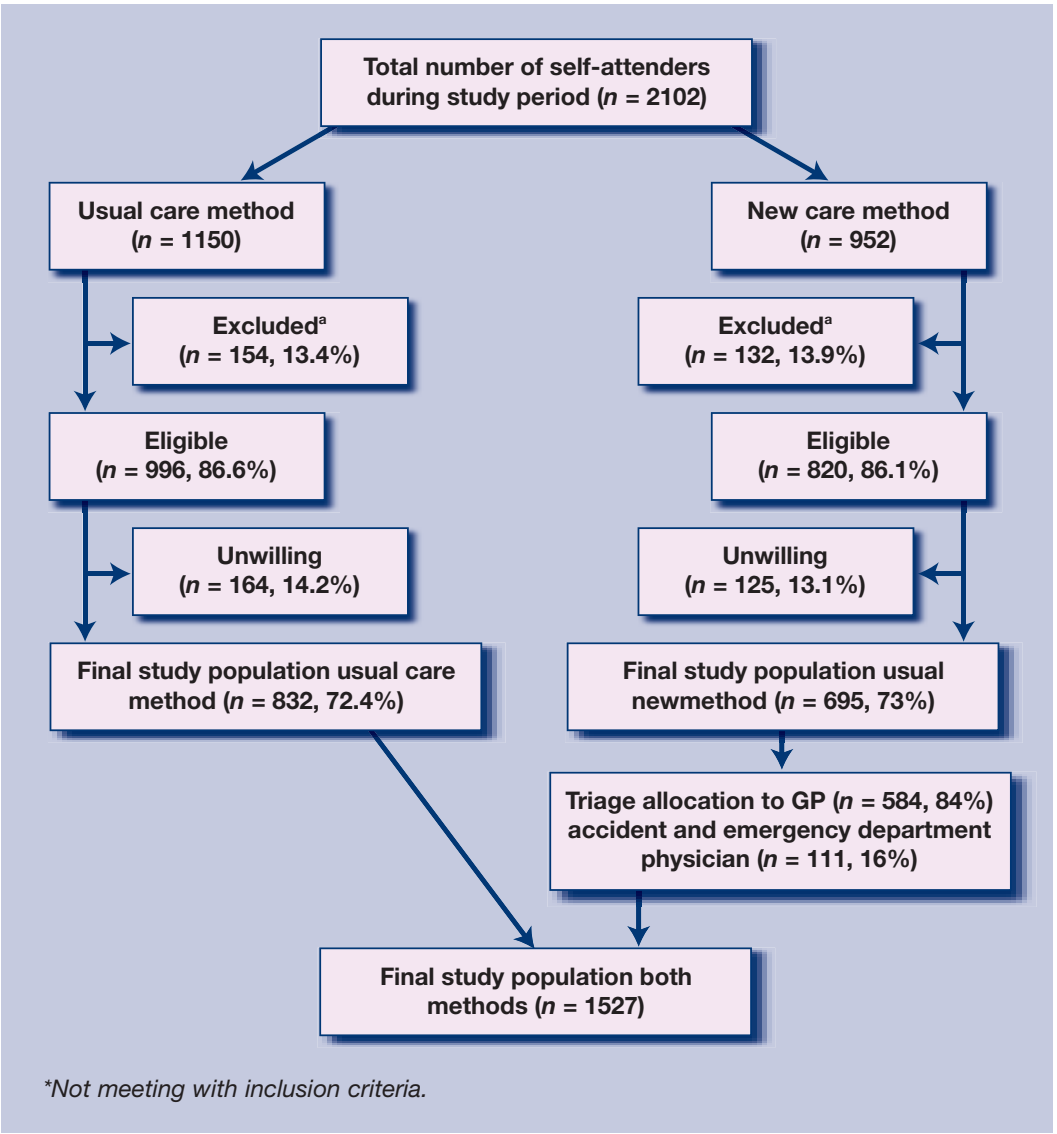

and were asked to verify the accident and emergency department diagnosis. If the GP's diagnosis was not concordant with that of the accident and emergency department, the two diagnoses were compared. This assessment was carried out independently in the new care method by two blinded researchers. If they did not agree, a third physician made an informed decision.

Potential confounders such as diagnosis, disease severity, and comorbidity were carefully recorded by the accident and emergency department physicians.

\section{Statistics}

Independent sample $t$-tests were used to compare time scores for both methods.

The sample size was calculated with the aim of detecting a relevant difference in the overall score for patient satisfaction. The study aimed to identify an increase of $10 \%$ (from $65 \%$ to $75 \%$ ) in patients who scored at least 6 out of 10 . With a one-sided statistical significance of $5 \%$ and a power of $80 \%$, two groups of 258 patients were needed to test the hypothesis that the experimental condition was better than the usual care method. A two-tailed test would require two groups of 329 patients. In order to detect relevant differences in interval or continuous scales it was decided to enrol 500 patients per experimental condition.

\section{RESULTS}

\section{Patients}

A total of 2102 patients visited the accident and emergency department during the study period. Of the $1823(87 \%)$ who were eligible for participation, 1527 (73\%) were willing to participate in the study (Figure 1); 832 patients were included during the control period and allocated to usual care, and 695 patients were included in the experimental period. In the intervention group, $84 \%$ were allocated to the GP and $16 \%$ primarily to the accident and emergency department physician. The two groups (control and intervention) were compared with regard to the distribution of demographic characteristics and diagnoses, in order to check for potential confounding. The baseline characteristics are shown in Table 1. Patients in the two groups were comparable.

\section{Patient satisfaction}

The patients treated with the new care method were significantly more satisfied with their accident and emergency department visit, and particularly so with regard to treatment received from the doctor and the nurse. Satisfaction with regard to factors that were stable over the two methods was similar (such as access to the hospital or treatment by other 
disciplines). The results of the mean scores per item are shown in Table 2.

\section{Additional diagnostic tests and therapeutic treatments}

Additional diagnostic tests were carried out for $45 \%$ of the patients in the usual care method versus in $32 \%$ in the new care method. This is a difference of 13\% $(P<0.001)$. Table 3 lists the diagnostic tests requested by the doctors and executed by laboratory assistants. The percentage of patients who had $X$-rays in the usual care method was $42.8 \%$, and in the new care method it was $29.8 \%,(P<0.001)$.

With regard to therapeutic treatments (for example, incisions and stitches), $48.5 \%$ of the patients in the new care method received no treatment, compared to $40.5 \%$ of the patients in the usual care method $(P=0.0013)$.

\section{Aftercare}

The study also investigated who the patients were referred to for aftercare: the number of patients referred to their GPs for aftercare increased by $17 \%$ in the new care method, and the number of patients referred to outpatient clinics decreased by $17 \%$.

\section{Quality of the diagnosis}

Data on 1105 patients were available to assess the quality of the diagnosis (GP-accident and emergency department concordance versus discordance of diagnosis). The frequency distribution of diagnoses is presented in Table 4. Eight patients in the control group (1.3\%) had a relevant different second diagnosis made by their own GP, compared to seven patients in the experimental group (1.5\%).

Table 5 shows the specific accident and emergency department diagnoses that were discordant with the GP diagnoses. In the two conditions, the proportion of concordance and the characteristics of the discordant diagnoses were comparable, and there was no indication of any decrease in diagnostic quality in the experimental condition. The two researchers agreed in all cases of relevant discordance.

\section{Process and treatment time}

The mean process time in the accident and emergency department was 93 minutes during the usual care period and 69 minutes during the intervention period. The difference of 24 minutes is highly significant $(P<0.001)$. The mean treatment times were 60 and 35 minutes, respectively (difference 25 minutes), and this difference was also highly significant $(P<0.001)$. The distribution of treatment time in blocks of 10 minutes is shown in Figure 2 and Table 6 . In the usual care method,
Table 1. Baseline characteristics by experimental condition.

\begin{tabular}{|c|c|c|c|c|}
\hline \multirow[b]{2}{*}{ Characteristics } & \multicolumn{2}{|c|}{$\begin{array}{l}\text { Usual care method, } \\
\qquad N=550\end{array}$} & \multicolumn{2}{|c|}{$\begin{array}{c}\text { New care method, } \\
\qquad N=519\end{array}$} \\
\hline & $n$ & $\%^{a}$ & $n$ & $\%^{a}$ \\
\hline Male & 257 & 49 & 274 & 53 \\
\hline Dutch nationality & 434 & 88 & 411 & 85 \\
\hline \multicolumn{5}{|l|}{ Age (years) } \\
\hline $5-14$ & 47 & 9 & 45 & 9 \\
\hline $15-24$ & 115 & 21 & 106 & 20 \\
\hline $25-44$ & 188 & 34 & 207 & 40 \\
\hline $45-64$ & 135 & 25 & 105 & 20 \\
\hline$\geq 65$ & 59 & 11 & 50 & 10 \\
\hline \multicolumn{5}{|l|}{ Education } \\
\hline Intermediate & 124 & 27 & 131 & 30 \\
\hline Higher & 167 & 36 & 147 & 33 \\
\hline Academic & 75 & 16 & 93 & 21 \\
\hline \multicolumn{5}{|c|}{ Medical history (number of chronic diseases) ${ }^{\mathrm{b}}$} \\
\hline 0 & 372 & 68 & 367 & 71 \\
\hline 1 & 133 & 24 & 117 & 23 \\
\hline 2 & 30 & 6 & 23 & 4 \\
\hline$\geq 3$ & 15 & 3 & 12 & 2 \\
\hline
\end{tabular}

aMissing data not shown. ${ }^{\mathrm{E} E x a m p l e s}$ of chronic diseases are diabetes, asthma, multiple sclerosis, and Parkinson's disease.

$20.1 \%$ of all accident and emergency department patients had been treated within 20 minutes, and $57 \%$ had been treated within 1 hour. In the new care method, $55.8 \%$ of all accident and emergency department patients received treatment within 20 minutes, and $80.1 \%$ received treatment within 1 hour. In the interpretation of the time differences, the GP has to be considered as an addition and not a substitution of staff members.

\section{DISCUSSION}

\section{Summary of main findings}

An experimental comparison of the effectiveness and quality of care of a new care method in the accident

Table 2. Patient satisfaction by experimental condition.

\begin{tabular}{lcccc} 
& \multicolumn{2}{c}{ Average scores } & & \\
\cline { 2 - 4 } & $\begin{array}{c}\text { Usual care } \\
\text { method }\end{array}$ & $\begin{array}{c}\text { New care } \\
\text { method }\end{array}$ & Difference & 95\% Cl \\
\hline Total visits to VUmc & 7.33 & 7.74 & 0.40 & 0.25 to 0.56 \\
\hline Reception & 7.25 & 7.66 & 0.40 & 0.25 to 0.56 \\
\hline Treatment by nurse & 7.74 & 7.92 & 0.18 & 0.04 to 0.32 \\
\hline Treatment by doctor & 7.68 & 8.11 & 0.44 & 0.28 to 0.60 \\
\hline Emotional support & 7.22 & 7.82 & 0.60 & 0.33 to 0.87 \\
\hline Other disciplines & 7.05 & 7.12 & 0.07 & -0.22 to 0.35 \\
\hline Autonomy & 7.11 & 7.49 & 0.38 & 0.11 to 0.66 \\
\hline Information & 7.30 & 7.66 & 0.35 & 0.18 to 0.53 \\
\hline Access to VUmc & 7.00 & 7.07 & 0.07 & -0.12 to 0.27 \\
\hline Aftercare & 7.27 & 7.55 & 0.29 & 0.08 to 0.49 \\
\hline
\end{tabular}

${ }^{a} V U m c=V U$ University Medical Center. 


\begin{tabular}{|c|c|c|}
\hline & $\begin{array}{c}\text { Usual care } \\
\text { method, } n(\%)\end{array}$ & $\begin{array}{c}\text { New care } \\
\text { method, } n(\%)\end{array}$ \\
\hline Number of patients & $832(100)$ & $695(100)$ \\
\hline No diagnostic test & $438(52.6)$ & 456 (65.6) \\
\hline Diagnostic test(s) & $394(47.4)$ & $239(34.4)$ \\
\hline \multicolumn{3}{|l|}{ Laboratory: } \\
\hline Haematology & $54(6.4)$ & $46(6.6)$ \\
\hline Clinical chemistry & $48(5.8)$ & $38(5.5)$ \\
\hline Other & $69(8.3)$ & $52(7.5)$ \\
\hline X-ray & $356(42.8)$ & $207(29.8)$ \\
\hline Endoscopy & $5(0.6)$ & $2(0.3)$ \\
\hline Ultrasonography & $17(2.0)$ & $25(3.6)$ \\
\hline CT-scan & $3(0.4)$ & $7(1.0)$ \\
\hline MRI & $3(0.4)$ & $0(0)$ \\
\hline ECG & $17(2.0)$ & $11(1.6)$ \\
\hline
\end{tabular}

$C T=$ computerised tomography. $E C G=$ electrocardiogram. $M R I=$ magnetic resonance imaging .

Table 4. Frequency distribution of diagnoses by care method.

\begin{tabular}{lcc} 
& $\begin{array}{c}\text { Usual care } \\
\text { method, } n(\%)\end{array}$ & $\begin{array}{c}\text { New care } \\
\text { method, } n(\%)\end{array}$ \\
\hline Skin & $229(27.5)$ & $161(23.1)$ \\
\hline Eye & $55(6.6)$ & $48(6.9)$ \\
\hline Ears, nose, throat & $36(4.3)$ & $25(3.6)$ \\
\hline Lung & $5(0.6)$ & $7(1.0)$ \\
\hline Heart & $4(0.5)$ & $4(0.6)$ \\
\hline Abdomen & $33(4.0)$ & $37(5.3)$ \\
\hline Arm contusion & $125(15.0)$ & $108(15.5)$ \\
\hline Arm fracture & $76(9.1)$ & $48(6.9)$ \\
\hline Leg contusion & $134(16.1)$ & $132(19.0)$ \\
\hline Leg fracture & $25(3.0)$ & $18(2.6)$ \\
\hline Gynaecological & $2(0.2)$ & $4(0.6)$ \\
\hline Multiple trauma & $0(0)$ & $1(0.1)$ \\
\hline Rest & $106(12.7)$ & $95(13.6)$ \\
\hline Missing & $2(0.2)$ & $8(1.1)$ \\
\hline
\end{tabular}

and emergency department was carried out, evaluating the involvement of a GP in the staff of the accident and emergency department and triage by a nurse. This new method turned out to be considerably more satisfying for patients and much more effective than usual care in terms of waiting time and treatment time, without decrease in the quality of diagnosis.

\section{Strengths and limitations of the study}

The before and after design allowed this study to be carried out in a busy accident and emergency department. A randomised clinical trial would have caused many practical problems, and would also have disturbed the daily practice in an unacceptable way. It was expected that a before and after design would lead to a good response rate, which was, indeed, the case. A randomised controlled trial design would have been the design of choice in order to guarantee comparability of the two study conditions. However, evaluation of the baseline characteristics of the patients in the two categories showed that they were highly comparable under the design chosen.

The experimental condition of the study was open to patients and staff. A beneficial effect of being under study (Hawthorne-effect) could have occurred, but probably equally in both conditions. It was not expected to bias potential differences in effect.

In the experimental condition, a GP was added to the usual staff (five members). This increased the human capacity of the staff. Of course, this addition in itself will have an effect of decreasing the total accident and emergency department process time, but the observed decrease ( 25 minutes) exceeded by far any reduction in treatment time due to extra staff.

Patients expressed more satisfaction in the intervention group, with an emphasis on reception, treatment by the physician, and emotional support. Satisfaction with regard to two outcomes that had not been changed by the intervention ('care by other medical professionals' and 'access to the hospital') did not vary over the categories. This underlines the effect of the intervention on patient satisfaction.

\section{Comparison with existing literature}

The inappropriate use of accident and emergency departments has been discussed widely. . $^{2,511-13}$ However, health providers and patients have different opinions about the appropriateness of accident and emergency department use. General societal and cultural factors determine healthcare-seeking behaviour, and interventions to reduce the amount of inappropriate use are expected to fail.

Therefore, the strategy should focus more on enhancing adequacy of care, and less on matching healthcare-seeking behaviour to the services. The care should preferably be adapted to meet the demands.

\section{Implications for future research and clinical practice}

It is interesting to see that GPs can improve the efficiency and effectiveness of the care provided in the traditionally hospital-related accident and emergency department. Further analysis of the elements that contribute to the effectiveness of the GP care has to be undertaken. It can be assumed that they are related to the way in which GPs deal with diagnostic uncertainty, their emphasis on the informative value of the medical history of the 
Table 5. Quality of diagnosis: relevant discordant diagnoses.

Accident and emergency department diagnosis

\begin{tabular}{|c|c|}
\hline Usual care method & Second diagnosis GP \\
\hline 1. Contusion foot & Gout \\
\hline 2. Aspecific chest pain & Angina pectoris \\
\hline 3. General malaise & Hernia diaphragmatica \\
\hline 4. Oesophagitis by NSAIDs & Angina pectoris \\
\hline 5. Contusion of finger & Infectious arthritis \\
\hline 6. Vasovagal attack & Severe anaemia \\
\hline 7. Constipation & Abnormality of the right kidney \\
\hline 8. Contusion left trunk side & Contusion of left trunk side and concussion of the brain \\
\hline \multicolumn{2}{|l|}{ New care method } \\
\hline 9. Swelling neck & Contusion left shoulder \\
\hline 10. Muscle pain in calf & Psychosis \\
\hline 11. Gastroenteritis, appendicitis, inflammatory bowel disease & Muscle pain abdominal wall \\
\hline 12. Distortion right knee & Rupture of the anterior cruciate ligament \\
\hline 13. Contusion left wrist joint & Radial fracture \\
\hline 14. Cervical disc hernia or carpal tunnel syndrome & Epicondylitis \\
\hline 15. Contusion of the hand & Fracture of the thumb \\
\hline
\end{tabular}

NSAIDs = non steroidal anti-inflammatory drugs.

patient, and their use of time to monitor the natural course of symptoms.

Inappropriate accident and emergency department use is handled more effectively with this strategy than with interventions directed towards changing the healthcare-seeking behaviour of patients. It is hoped that the study findings will lead to the adaptation of accident and emergency department care models and more experiments in care provision in which the collaboration of medical specialists and GPs will be equally successful.

\section{Funding body}

This research was funded by AGIS healthcare insurance company and VU University Medical Center.

\section{Ethical approval}

The study received ethical clearance from the Human Medical Ethics Committee (METC) of the VU University Medical Center.

\section{Competing interests}

The authors have stated that there are none.

\section{Acknowledgements}

We thank the participants in this study for their cooperation We also thank staff and personnel of the Accident and Emergency Department of the VU Medical Center. The study was partially funded by Agis zorgverzekeringen (Agis insurance company, Amersfoort, Netherlands) and partially by the VU University medical center.

\section{Discuss this article}

Contribute and read comments about this article on the Discussion Forum: http://www.rcgp.org.uk/bjgp-discuss

\section{REFERENCES}

1. Jaarsma-van Leeuwen I, Hammacher ER, Hirsch R, Janssens M. [Patients without referral treated in the emergency room: patient characteristics and motives.] [in Dutch] Ned Tijdschr Geneeskd 2000; 144(9): 428-431.

2. Dale J, Green J, Reid F, Glucksman E. Primary care in the accident and emergency department: I. Prospective identification of patients. BMJ 1995; 311(7002): 423-426.

3. Laursen MB, Jensen HP. [Many patients treated in the emergency department could be treated by a general practitioner on call.] [in Danish] Ugeskr Laeger 1999; 161(33): 4624-4627.

4. Green J, Dale J. Primary care in accident and emergency and general practice: a comparison. Soc Sci Med 1992; 35(8): 987-995.

Figure 2. Treatment time by care method.

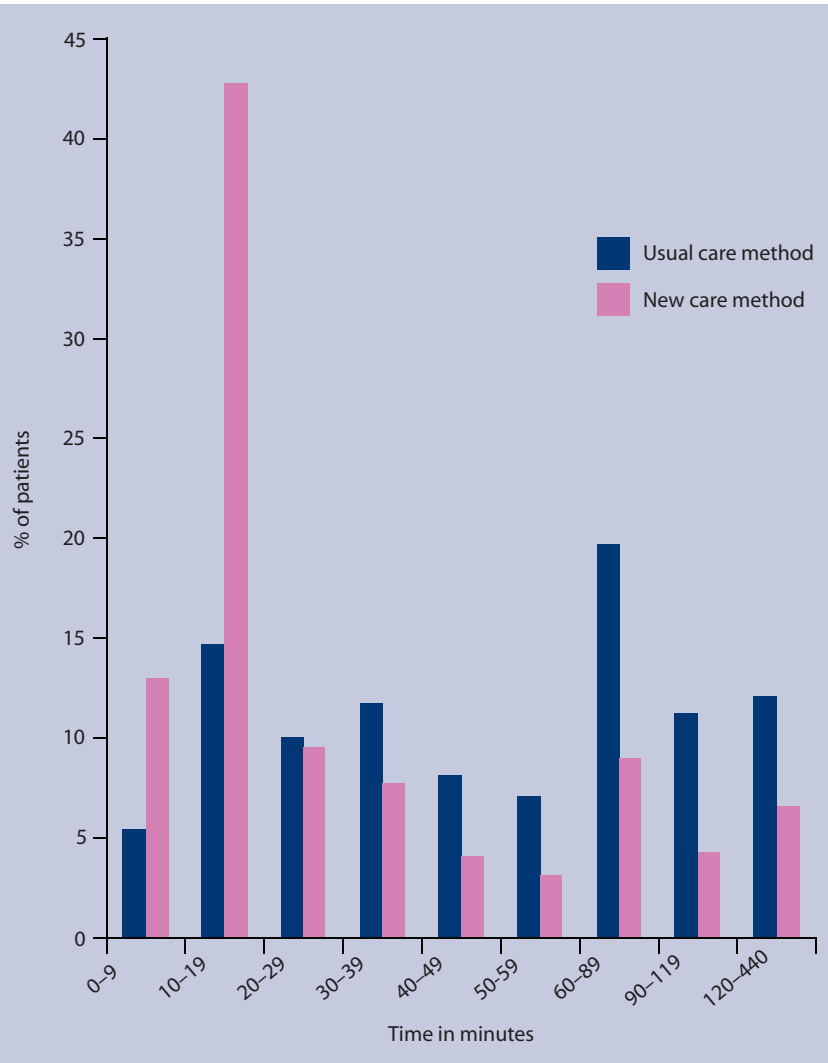




\section{Table 6. Treatment time distribution by experimental condition.}

\begin{tabular}{lcc}
$\begin{array}{l}\text { Treatment } \\
\text { time, minutes }\end{array}$ & $\begin{array}{c}\text { Usual care } \\
\text { method, } n(\%)\end{array}$ & $\begin{array}{c}\text { New care } \\
\text { method, } n(\%)\end{array}$ \\
\hline $0-9$ & $40(5.4)$ & $85(13.0)$ \\
\hline $10-19$ & $109(14.7)$ & $279(42.8)$ \\
\hline $20-29$ & $74(10.0)$ & $62(9.5)$ \\
\hline $30-39$ & $87(11.7)$ & $50(7.7)$ \\
\hline $40-49$ & $60(8.1)$ & $26(4.0)$ \\
\hline $50-59$ & $53(7.1)$ & $20(3.1)$ \\
\hline $60-89$ & $146(19.7)$ & $59(9.0)$ \\
\hline $90-119$ & $83(11.2)$ & $28(4.3)$ \\
\hline $120-440$ & $90(12.1)$ & $43(6.6)$ \\
\hline
\end{tabular}

5. Lega F, Mengoni A. Why non-urgent patients choose emergency over primary care services? Empirical evidence and managerial implications. Health Policy 2008; 88(2-3): 326-338.
6. Dale J, Lang H, Roberts JA, et al. Cost effectiveness of treating primary care patients in accident and emergency: a comparison between general practitioners, senior house officers, and registrars. BMJ 1996; 312(7042): 1340-1344.

7. Roberts E, Mays N. Can primary care and community-based models of emergency care substitute for the hospital accident and emergency (A\&E) department? Health Policy 1998; 44(3): 191-214.

8. Lee A, Hazlett CB, Chow S, et al. How to minimize inappropriate utilization of Accident and Emergency Departments: improve the validity of classifying the general practice cases amongst the A\&E attendees. Health Policy 2003; 66(2): 159-168.

9. Drijver R, Jochems $\mathrm{P}$ (eds). [Nederlands Triage Systeem. Towards an unequivocal triage.] [in Dutch]. Utrecht: NHG/LAMP/NVSHV/GGZ Nederland, 2006.

10. Visser A Ph. [The experience of stay in a general hospital.] [dissertation in Dutch]. Assen: van Gorkum, 1984.

11. Murphy AW. 'Inappropriate' attenders at accident and emergency departments II: health service responses. Fam Pract 1998; 15(1): $33-37$.

12. Martin A, Martin C, Martin PB, et al. 'Inappropriate' attendance at an accident and emergency department by adults registered in local general practices: how is it related to their use of primary care? J Health Serv Res Policy 2002; 7(3): 160-165.

13. Siminski P, Bezzina AJ, Lago LP, Eagar K. Primary care presentations at emergency departments: rates and reasons by age and sex. Aust Health Rev 2008; 32(4): 700-709. 